\title{
单型小麦雄性不育系的育成及其 育性㤥复性能的初步研究
}

\author{
张 改生 \\ (西北农业大学农学系, 陕西杨 陵 712100)
}

\section{关键词山羊草、雄性不嵩、恢复性}

常胁恒一郎等 ${ }^{[1-3}$ 报道, 用核置换回交法, 将小麦 5 个种的 12 个不同核型导人小麦局和山 单草属 35 个种 ( 43 个系统) 的细胞质中, 由于不同核质间的专一互作, 产生的核质杂种在育性 反应及部分主要农艺性状表现上具有明显的特异性, 依此将参试的 35 个种 (43 个系统)的细 胞质分为 11 个类型. 其中 3 个类型的 4 种细胞质型, 即 $G 、 M^{u} 、 S^{v}$ 和 $D^{2}$ 在雄性不育和杂 种优势利用研究中最具应用价值. 但是, 现已报道的电 $G$ 质型培育的提型和由 $S^{v}$ 质型培育的 粘、易型小麦雄性不育系, 前者因恢复源少, 种子坡缩及发芽率低等缺点, 至今米能大面积应用 于生产的; 后者虽具有恢复源比较广泛, 种子饱满和发芽率高等特点, 可较好地克服提型长期 存在的一些较难克服的缺点, 然而又遇到一些新的问题, 如: (1) 绝大多数 $1 \mathrm{~B} / 1 \mathrm{~K}$ 不育系及 其 $\mathrm{F}_{1}$ 杂种都产生有一定比率的单倍体(部分组合甚至高达 $80 \%$ 以上); 与此同时,一个连带反 应是不育系及其杂种生长势下降。（2）育性恢复度变异较大 ${ }^{[5-8]}$. 不克服这些缺点, 粘、易型 不育系应用于生产仍有一定困难. 至于后两种质型, $\mathrm{D}^{2}$ 属于光敏感不育, 易受环境条件的影 响 ${ }^{[9]} . \mathrm{M}^{u}$ 国内外至今尚末见有培育成功的报道. 因此,小麦杂种优势利用中, 一方面除继续 研究解决提型和粘、易型不育系存在的上述缺点外, 另一方面深人探索新的不育类型, 尽快选 出一种易保持、极易恢复, 而且育性稳定、恢复度高、种子饱满, 对生长发育无不良影响, 杂 种优势强的优良不育类型, 仍是至关重要的问题. 有鉴于此, 作者对 $\mathrm{M}^{\mathrm{u}}$ 质型的单芒山羊草 (Aegilops uniaristata) 胞质育性表现及其在杂种小麦中的应用价值专门进行了研究, 得出一 些初步结果.

\section{一、砎科和方法}

以优良可育异质小麦品种 (Ae. uniaristata)-Chris (从美国北达科他州立大学引进 ${ }^{[6]}$ ) 为 母本, 两个不同细胞质的正反杂交后代株(系)为父本: 父本 1 为 $[\mathrm{ms}$ (Triticum aestivum)-矮 秆早 $\times$ (Ae. squarrosa)-84-241] $\mathrm{F}_{1}$ 中的高不育植株 (平均自交结实率为 $16.3 \%$ ), 父本 2 为 (Ae. squarrosa)-84-241 $\times$ [ms (T. aestivum)-婑秆早 $\times($ Ae. squarrosa $)-84-241] \mathrm{F}_{1}$ 的后代 株(系). 其中 $\mathrm{ms}($ T. aestivum $)$-矮秆早是从普通小麦品种矮秆早中发现的高不育株, 经多年 研究培育出的高代不育系, 曾与多种材料测交, 几乎杂种育性都表现正常恢复; 但其不育性难 以完全保持, 原保持系 (Ae. squarrosa)-矮秆早 [(Ae. squarrosa)-Gaines（从日本木原生物

本文1991年7月10日收到. 1991 年 10 月 10 日收到修改稿.

第 7 期

科学 通 报 
㖄究所引进) ×矮秆早高不育株, 再以父本多次回交后的稳定品系] 与其最高回交世代已超过 20 代, 不育度总稳定在 $95 \%$ 左右, 只有将其高不育植袾严格套袋自交才可分密出完全不育 株系. (Ae. squarrosa)-84-241 来自 (Ae. squarrosa)-矮秆早 X普通小麦品系 78-30-322, 再 自交纯化后的稳定品系, 与 $\mathrm{ms}$ ( T. aestivum)-矮秆早杂交表现高不育. 基于此, 父本 1 和 2 核中都含有特定不育基因,相互又是正反杂交,因而父本 1 与母本杂交可将其不育基因导人 异质小麦 (Ae. uniaristata)-Chris 胞质背景, 以考察其育性反应; 而父本 2 核中不育基因在 Ae. squarrosa 可育质背景可通过重组和成对回交而获得稳定保持系. 具体方法是: 先以母 本与父本 1 进行杂交, $F_{1}$ 严格套袋自交, $F_{2}$ 选择全不育株再与父本 2 进行成对连续置换回 交. 最后, 以获得的稳定全不育系与一些小麦品种(系)进行广泛测交, 考察其保持性和易恢复 性. 育性鉴定是在成熟后考察主茎穗自交结实率,部分材料用醋酸洋红压片镜检花粉粒. 试验自 1984 年开始, 在西北农业大学试验农场进行, 少数材料于温室加代.

\section{二、结果与讨论}

\section{1. $F_{1} 、 F_{2}$ 与回交后代的育性表现}

以母本与父本 1 杂交, 所得 $F_{1}$ 表现可育. 但可育度很低, 平均自交结实率只有 $26.3 \%$ 。 $F_{1}$ 自交, $F_{2}$ 育性发生分离, 共获得 53 株, 其中 42 株为可育, 11 株表现全不育, 可育与不育的 比例接近 $3: 1$. 分离出的全不育株再用父本 2 回交, $\mathrm{BC}_{1}$ 到 $\mathrm{BC}_{4}$ 均有育性分离, 但后代不育 㧣率大幅度提高,到 $\mathrm{BC}_{5} 、 \mathrm{BC}_{6}$ 便表现全不育(表 1). 其花药瘦小,干秕, 花丝伸长露出䚙外, 但不开裂; 内含少量花粉, 醋酸洋红染色时仅见到稀少内含物; 花粉一般都停止在单核期或二 核期; 精核表现畸型, 无生育能力. 成熟后考察其主茎穗自交结实率全为零, 不育株率和不育 度均为 $100 \%$; 但人工或放任授粉, 结实正常, 种子饱满, 表明雌嘭发育正常. 继续用原父本回 交便成为新的稳定的单型小麦雄性不育系 (图 1). 这些结果表明, 单芒山羊草细胞质中肯定 含有对应父本 1 和父本 2 核内不育基因的质内不育位点, 否则, 可完全保持的稳定单型不育系 是难以获得的. 而异质小麦 (Ae.uniaristata)-Chris 核内也一定含有对应单芒山羊草细胞 质内不育基因位点的可育基因, 否则, 其自身的育性不会正常, 表 1 中 $F_{1}$ 和 $F_{2}$ 的育性表 现正好证实了这一点, $\mathrm{F}_{1}$ 表现可育是因为 $\mathrm{F}_{1}$ 核型中仍保留有异质小麦 (Ae. uniaristata) -

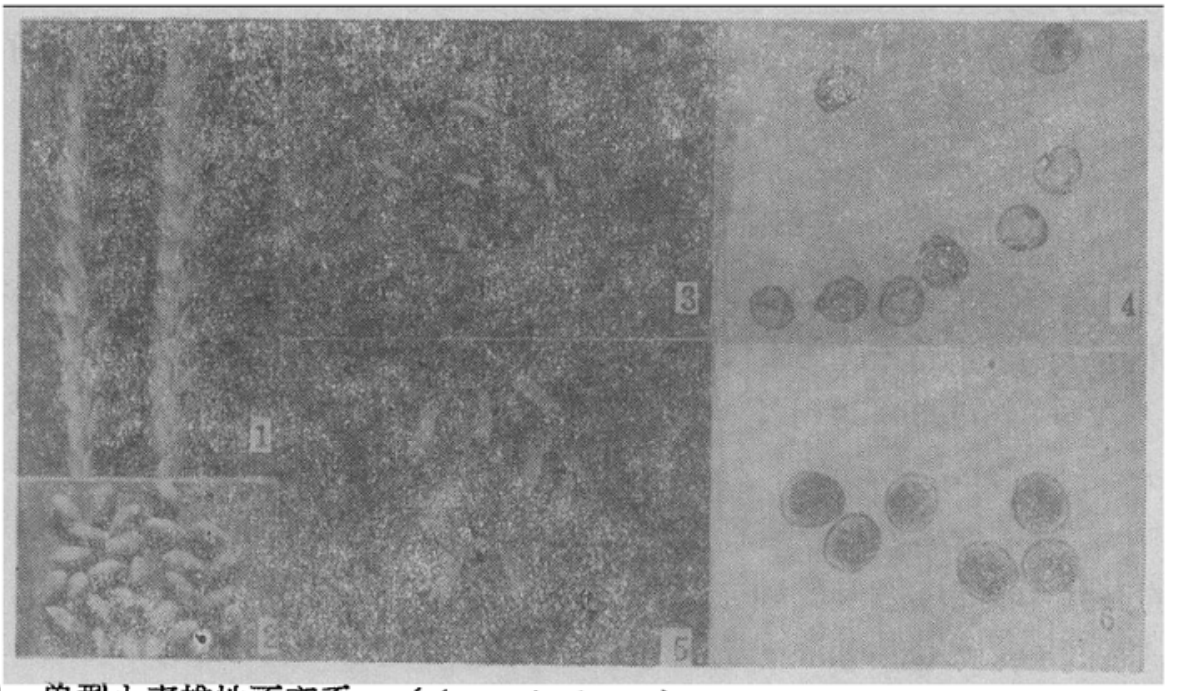

图 1 单型小麦雄性不育系 $\mathrm{ms}($ Ae. uniariszata $)-88-115$ 的㯖子 (1)、种子 (2) 及其 败育花药 (3) 与败育花粉粒 (4) 和保持系的可育花药 (5) 与可育花粉粒 (6) 


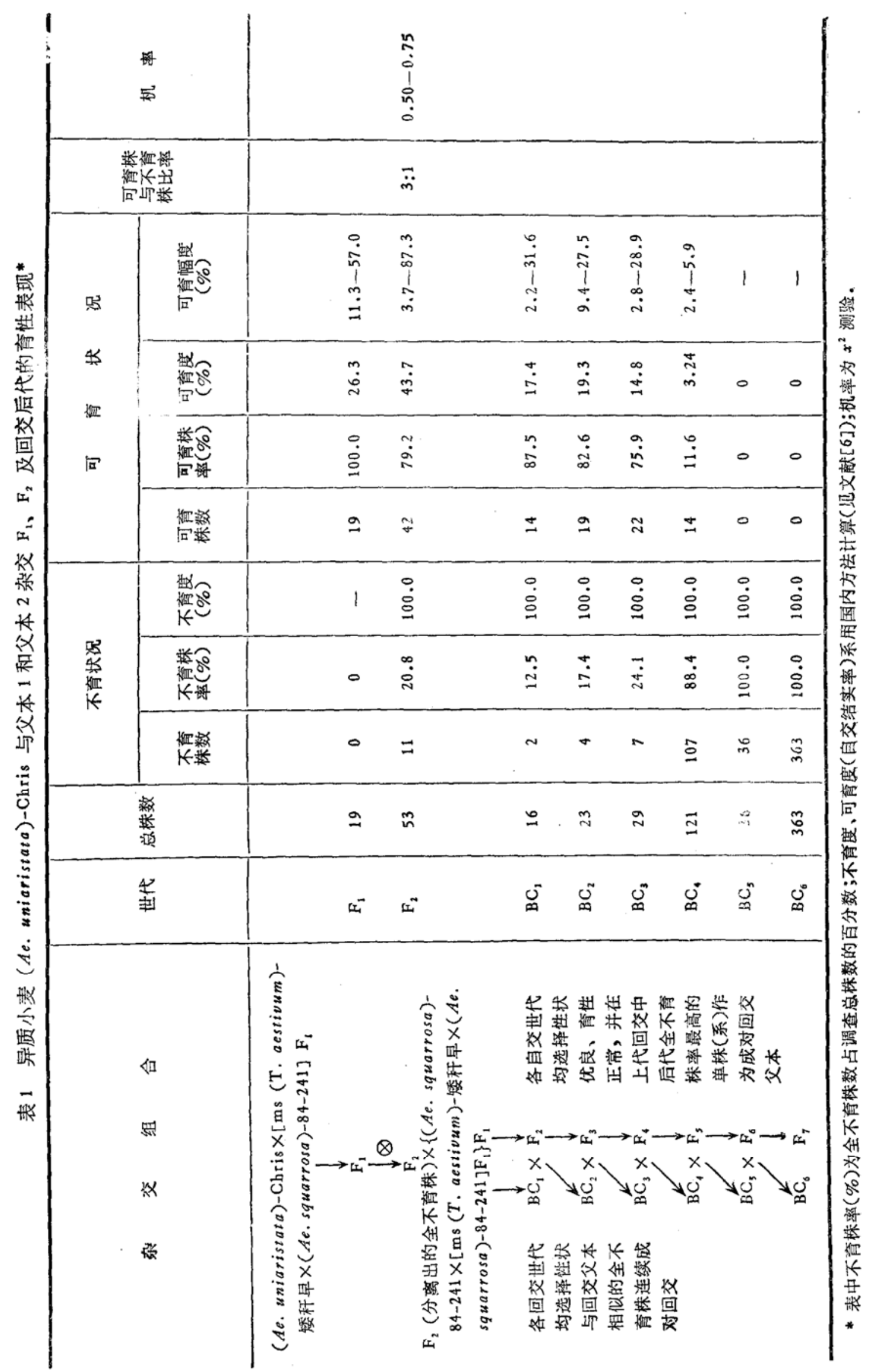


Chris $1 / 2$ 核遗传物质所组成； $F_{2}$ 所发生的育性分离是父本 1 对应单些山羊草细胞质内不育 基因位点的核内不育基因重新组合与纯化的结果. 但这里一定有微效可育基因被“淘汰”, 因 为用单型不育系直接与 (Ae. squarrosa) -84-241 杂交和连续回交, 低、高世代脩性总有分 离, 而且各代分离出的可育株平均自交结实率一直稳定在 $10 \%$ 左右. 表 1 回交资料也证实这 一点, $\mathrm{BC}_{1}-\mathrm{BC}_{4}$ 均有育性分离, 原因就是父本 2 在自交低世代核内微效可育基因尚未完全被 “淘汰”; $\mathrm{BC}_{5} 、 \mathrm{BC}_{6}$ 育性不再分离表现全不育, 说明父本 2 核内微效可育基因已在成对回交中 被“淘汰”掉.

要说明的是, 表 $1 \mathrm{~F}_{2}$ 育性近似 3:1 分离是因为父本 1 中两亲本核型仅以主效不育位点而 言是相同的; 否则, $F_{1}$ 是不会表现高不育的。因此, 表 1 中母本与父本 1 杂交, 论其核内育性 位点, 实质是母本可育基因与父本 1 同一位点不育基因的重组与分离,表明单型不育性主姴受 1 对主效隐性基因控制, 易于转育和恢复. 不过 $\mathrm{F}_{2}$ 育性分离是否会受到(Ae. squarrosa)-84241 中所含微效可育基因或杂合遗传背最的影响, 值得进一步探明.

\section{2. 童㤠不济添持性啝恢复性测定}

以表 1 中 $\left(\mathrm{BC}_{5}\right.$ 和 $\left.\mathrm{BC}_{6}\right)$ 育成的单型全不育系 $\mathrm{ms}$ (Ae. uniaristata)-88-115 与 78 个小 麦品种(系)进行测交, 结果见表 2 .

(1) 保持性. 78 个组合中, 4 个测交亲本 (89-10-139,89-7-97, 90-7-7, 90-7-88) 的后代 表现全不育, 自交结实率全为零,不育度和不育株率均为 $100 \%$, 占测交组合的 $5.1 \%$. 表明栽 培小麦中的少数品种(系)在自然情况下核内就已存在有对应单型不育质源并与测交母本不育 系相同的核内不育位点, 否则, 测交 $\mathrm{F}_{1}$ 是不会表现全不育的. 当然, 这些品种的细胞质肯定 不同于单芒山羊草,它们的胞质对应其核内不育位点是可育的,否则，自身也将表现不育. 另 外,上述 4 个来本都为栽培品种, 尤其 89-7-97 和 90-7-7 是正待推广的优良品系,不仅可直接 用来组配强优组合, 也为在品种(系)内继续篎缝或以此重新转育更优良的单琶不育系奠定了 基粗。

表 2 单型不育系保持性和恢复性的测定结果*

\begin{tabular}{|c|c|c|c|c|}
\hline 育性水平(自交结实) & 组合数 & $\begin{array}{c}\text { 占总组合数 } \\
(\%)\end{array}$ & $\begin{array}{c}\text { 可育幅臂 } \\
(\%)\end{array}$ & $\begin{array}{c}\text { 号均结笑率 } \\
(\%)\end{array}$ \\
\hline 全不育 $(0, \%)$ & 4 & 5.1 & - & - \\
\hline 高不䆚 $(1-20)$ & 26 & 33.3 & $2.4-19.6$ & 14.1 \\
\hline 半不育 $(21-50)$ & 34 & 43.6 & $20.9-49.9$ & 39.7 \\
\hline 高 育 $(51-80)$ & 7 & 9.0 & $54.7-76.3$ & 64.9 \\
\hline 全 育 $(8 \mathrm{l}-100)$ & 7 & 9.0 & $80.6-94.7$ & 84.3 \\
\hline
\end{tabular}

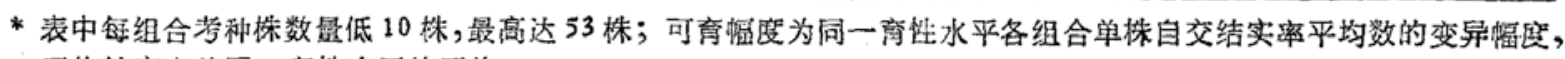
平均结实率为同一育性水平的平均.

（2）恢复性. 结果表明单型不裔系是一个恢复源很广泛的不育类型. 除前述 4 个测交亲 本后代表现全不育外, 其余 74 个后代均表现可育, 占测交总数的 $94.9 \%$ 。值得注意的是组 合间恢复度有明显的差异, 平均结实率从高不育到全育呈连续性变昇, 育性幅度在 2.4一 $94.7 \%$ 之间。其中半不育占的比例最大, 为 $43.6 \%$; 高不育次之, 为 $33.3 \%$; 高育和全育较小, 各为 $9.0 \%$. 这种现象的直接原因有待深人研究. 仅从表 2 的育性表现, 可认为与各测交父本 核型妕育性恢复基因的组成有关, 在测交 $\mathrm{F}_{1}$ 中它们是以四种不同形式决定育性的表现: 一 是核型中既含有主效恢复基因又含有增强育性的修饰基因; 二是只有主效恢复基因; 三是除含 
有主效恢复基因外还含有育性抑制基因; 四是仅带有增强育性的修饰基因而无主效恢复基因. 其 $\mathrm{F}_{1}$ 中的 4 种不同育性的平均结实率依次为 $81-100 、 51-80 、 21-50 、 1-20 \%$. 当然, 也不 能排除不同父本核内育性基因以外的㤥遗传背景和不育系结合后重组的新遗传背景的影响, 或由此产生的各特定基因型和环境的特殊互作关系与恢复性有关.

\section{3. 单型不育与其它不育类型的区别}

和提型 (包括提类的 $\mathrm{P} 、 \mathrm{~S}$ 型及大部分普通小麦细胞质不育类型 ${ }^{[10]}$ ) 比较, 恢复源相当广 泛, 种子正常饱满是单型不育系最突出的特点 (表 2, 图 1、2). 和粘型 (包括沾类的易、偏 型 ${ }^{[101)}$ ) 比较, 恢复源同样更广泛亦是一个特别明显的特点, 如一些 $1 \mathrm{~B} / 1 \mathrm{R}$ 易位系或其衍生品 系 77(2)、陕 7859、78(2)、8222、86-2-46 等均是粘型的保持系, 而在本试验中却都是单型的自 然恢复系; 粘型的一些非 $1 \mathrm{~B} / 1 \mathrm{R}$ 恢帞系, 如陕农 17、小偃 6 号、阿勃、89-2-416 等也都是单型 的自然恢复系. 尤其是单型和粘、偏型之间还存在一定的互作关系, 如在上述列举的 $1 \mathrm{~B} / 1 \mathrm{R}$ 易位系外, 89-7-97 对粘型是恢复的, 而对单型是全不育的; E32-1 对偏型是全不育的, 而对 单型却是恢复的; 89-10-139 对偏型是恢复的, 并具有很强的杂种优势, 而对单型却是不育的. 其次,单型不育系生长正常,所有供试材料后代没有出现 1 株单倍体, 完全克服了粘、易型不 育系及其 $F_{1}$ 杂种常以不同比率产生单倍体和生长势弱的缺点.

\section{三、结 论}

综上所述, 单型小麦雄性不育系既不同于粘类, 更不同于提类, 是一个稳定的新不育类型。 突出的表现特点是仅少数普通小麦品种(系)是其稳定的保持系, 而绝大多数对其不育性都具 有不同程度的恢复力; 并在这些广泛的恢复材料中, 恢复度高于 $80 \%$ 以上的恢复系比其它具 有较广泛饭复源的不育类型 ${ }^{[6]}$ (如粘型等)在普通小麦中占有较大的比例. 其次是长势正常, 种子饱满, 胞质无不良的挫影响。为莎种小麦与常规育种更约纨结合在一起, 把常规育种 的最新成就更存效地应用于杂种小麦, 加快杂种小唛的选育和生产应用创造了很有利的条 件.

致谢: 本研究先后得到李正德教授和杨天意副教授，南京农业大学吴兆苏教授和俞世詹教授的热情指 导,在此一并致谢.

\section{参考文蔏}

[1] Tsunewaki, K., Genetic Diversity of Cytoplasm in Triticum and Aegilops, Jap. Soc. Prom. Sci., Tokyo, 1980.

[2] Tsunewaki, K. et al., Proc. 6th Int. Wheat Genet. Symp., 1983, 1139-1144.

[3] Tsunewaki, K., Proc. 7th Int. Wheat Genex. Symp., 1988, 53-62.

[4]黄铁城,杂种小麦研究, 北京农业大学出版社, 1990 .

[5] Mukai, Y., Proc. 6th Int. Wheat Genet. Symp., 1983, 517-527.

[6] 张改生等,作物学报, 15(1989),1: 1-10.

[7] 张改生,陕西农业科学, 1989,6: 1-12.

[8] 蒋华仁等,中国农业科学, 21(1988),2: 95 .

[9] Tsunewaki, K. et al., $P B A, 58(1988)$, P701-N6399.

[10] 张改生等,陕西农业科学, 1990,3: 45-48. 